\title{
Epidemiology and disease characteristics of symptomatic choledocholithiasis in Sri Lanka
}

\author{
Waduthanthri Supun Lakmal De Silva ${ }^{1}$, Ajith Aloka Pathirana ${ }^{2}$, Thejana Kamil Wijerathne ${ }^{2}$, \\ Bawantha Dilshan Gamage ${ }^{2}$, Buddhika Kemiya Dassanayake ${ }^{3}$, and Mohan Malith De Silva ${ }^{2}$
}

\author{
${ }^{1}$ Post Graduate Institute of Medicine, University of Colombo, ${ }^{2}$ Department of Surgery, Faculty of Medical Sciences, \\ University of Sri Jayewardenepura, Colombo, ${ }^{3}$ Department of Surgery, Faculty of Medicine, \\ University of Peradeniya, Peradeniya, Sri Lanka
}

\begin{abstract}
Backgrounds/Aims: Published data on choledocholithiasis in Sri Lanka is scarce. This study was conducted to determine epidemiological, clinical and endoscopic characteristics of choledocholithiasis in Sri Lanka. Methods: This was a retrospective study of consecutive patients for a period of three years until April 2016. The sample included patients from many parts of the island. Patients were selected from the endoscopy database of the unit and the data were collected from the records of the patients. Results: A total of 253 patients were included in the study. The mean age of the patients was 53.6 years. Patients presented with obstructive jaundice $(58.5 \%)$, cholangitis $(25.3 \%)$, biliary colic or upper abdominal pain $(14.2 \%)$ and acute biliary pancreatitis $(1.8 \%)$. There were $26(10.3 \%)$ post cholecystectomy patients. Concomitant gallbladder stones were found in 173 patients $(68.4 \%)$. Juxta-papillary diverticula were found in 36 patients $(14.2 \%)$. Twenty-one $(8.3 \%)$ and nine patients $(3.6 \%)$ were found to have choledochal cysts and common bile duct strictures, respectively. Stones were commonly found in the distal common bile duct (68.4\%). A majority of the patients had a single stone $(47.8 \%)$. In 209 patients $(79.6 \%)$, the size of the largest stones measured between 0.5-1.5 cm. Conclusions: Choledocholithiasis is a disease affecting middle-aged population with predominance among females in Sri Lanka. Patients with symptomatic choledocholithiasis commonly present with obstructive jaundice. In the present study, most of the stones were formed in anatomically normal biliary systems. Stones were predominantly distal, single and measured $0.5-1.5 \mathrm{~cm}$ in size. The observed features were favorable features for successful endoscopic clearance. None of the patients included in the study had primary CBD stones according to the available criteria. (Ann Hepatobiliary Pancreat Surg 2019;23:41-45)
\end{abstract}

Key Words: Common bile duct stones; Symptomatic choledocholithiasis; Choledocholithiasis in Sri Lanka; Juxta-papillary diverticula; Primary common bile duct stones

\section{INTRODUCTION}

Common bile duct (CBD) stones cause significant morbidity to the patients and at times mortality. One in five of the population harbor stones in the gallbladder ${ }^{1}$ and concomitant common bile duct stones are found in $10-20 \%$ of the population with stones. ${ }^{1-3}$ About $50 \%$ of patients with choledocholithiasis are asymptomatic. ${ }^{1}$ Epidemiological data on symptomatic choledocholithiasis is sparse, and the available knowledge originates from data gathered from intraoperative cholangiography i.e., asymptomatic stones. ${ }^{4,5}$ There is a paucity of literature on symptomatic choledo- cholithiasis as a separate entity, with a description of the burden of the disease with respect to the associated complications. In Sri Lanka, intraoperative cholangiography is not widely practiced. Thus, patients with choledocholithiasis are mostly picked up when they are referred for therapeutic endoscopic retrograde cholangiopancreatography (ERCP), which is the preferred management option in Sri Lanka.

CBD stones are classified as primary and secondary stones depending on their predicted site of origin. A stone formed de novo in the CBD is considered as a primary stone, whereas a stone fallen out of the gallbladder is con-

Received: September 12, 2018; Revised: October 5, 2018; Accepted: October 7, 2018

Corresponding author: Waduthanthri Supun Lakmal De Silva

Post Graduate Institute of Medicine, University of Colombo, 1485/A/3, Joranis Peris Road, Kottawa North, Colombo 80300, Sri Lanka Tel: +94772332059, Fax: +94112160374,E-mail: supun85@gmail.com

Copyright (C) 2019 by The Korean Association of Hepato-Biliary-Pancreatic Surgery

This is an Open Access article distributed under the terms of the Creative Commons Attribution Non-Commercial License (http://creativecommons.org/ licenses/by-nc/4.0) which permits unrestricted non-commercial use, distribution, and reproduction in any medium, provided the original work is properly cited. Annals of Hepato-Biliary-Pancreatic Surgery • pISSN: 2508-5778 - eISSN: 2508-5859 
sidered a secondary stone. Pathogenesis of primary stones is still not fully understood. Moreover, the criteria for the categorization of CBD stone into primary and secondary stones are five decades old. ${ }^{6,7}$

\section{PATIENTS AND METHODS}

This was a retrospective study including patients referred to Colombo South Teaching Hospital (a tertiary care center for hepatobiliary disease) for endoscopic management of CBD stones from all parts of the country. All patients who underwent therapeutic ERCP for choledocholithiasis for the first time from April 2013 to April 2016 were included in the study. All patients fulfilled criteria to be categorized into the high-risk group of having CBD stone according to American Society of Gastrointestinal Endoscopy guidelines. ${ }^{8}$ Patients who underwent ERCP as a planned second or subsequent time and patients who were not found to have CBD stone during ERCP were excluded.

Patients were selected from the ERCP database of the unit. Data were collected from the records of the patients and cross-checked with endoscopic and cholangiography images. A proforma containing demographic, clinical, ultrasound scan (USS) and ERCP data for each patient was prepared. Data on intrahepatic duct dilatation (IHDD), CBD diameter, the number and size of stones, with their location in the biliary tree were recorded. In the case of the presence of multiple stones, the size of the largest stone was considered. For the analysis, the findings of cholangiogram were considered over USS findings. A per-

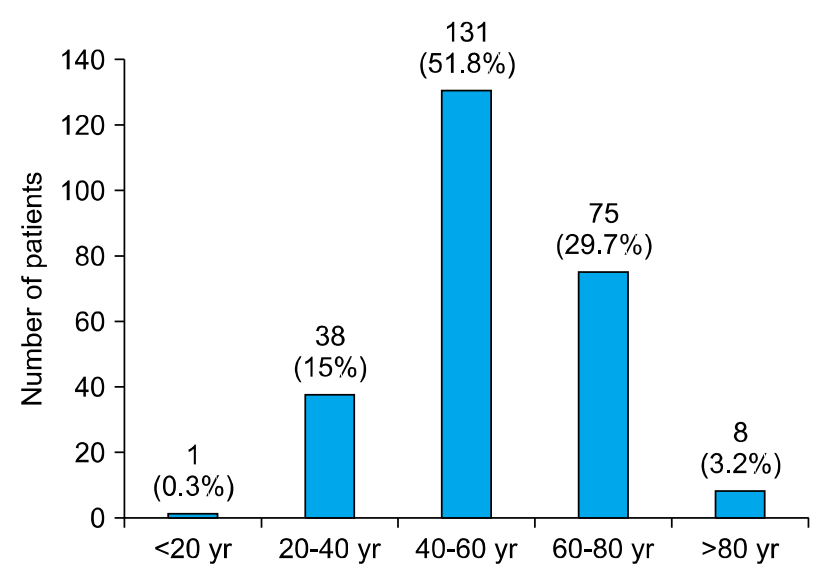

Fig. 1. Distribution of patients according to the age. sistent localized dilatation of CBD in cholangiogram was recognized as a choledochal cyst and a persistent localized narrowing was considered as a CBD stricture.

Data were analyzed using SPSS 20. According to the age, the patients were grouped into $\leq 20,20-40$, 40-60, $60-80$ and $\geq 80$ year's categories. Correlations of the epidemiological characteristics, clinical details, endoscopic and cholangiographic findings were studied.

\section{RESULTS}

\section{Epidemiology}

Out of 312 patients diagnosed with choledocholithiasis by ERCP, only 253 had adequate data for analysis. The mean age of the study population was 53.6 years (range $15-85$ years). The commonest age range was $40-60$ years (51.8\%) (Fig. 1). The male: female ratio was 41.1:58.9. The mean age for males was 58.8 years (SD 11.2) and for females was 50 years (SD 13.9). The difference between the mean ages of the patients was significant $(p<0.001)$.

\section{Clinical presentation}

Epidemiological characteristics of patients according to the mode of presentation are depicted in Table 1 .

The mean age of patients with cholangitis was significantly higher than that of patients with acute biliary pancreatitis or abdominal pain/biliary colic $(p=0.01)$. The majority of the patients with cholangitis $(85.93 \%)$ were diagnosed with severe sepsis at the time of ERCP. Out of the 36 patients with upper abdominal pain or biliary colic, $21(8.30 \%)$ patients were scheduled for cholecystectomy for symptomatic cholelithiasis and referred for pre-operative ERCP after inferring concomitant CBD stone.

Table 1. Distribution of patients according to the clinical presentation

\begin{tabular}{|c|c|c|c|c|}
\hline & $\begin{array}{l}\text { Obstructive } \\
\text { jaundice }\end{array}$ & Cholangitis & $\begin{array}{c}\text { Abdominal } \\
\text { pain/Biliary } \\
\text { colic }\end{array}$ & $\begin{array}{c}\text { Biliary } \\
\text { pancreatitis }\end{array}$ \\
\hline Total & $148(58.49 \%)$ & $64(25.29 \%)$ & $36(14.22 \%)$ & $5(1.79 \%)$ \\
\hline $\begin{array}{l}\text { Mean age } \\
\text { (years) }\end{array}$ & 55.3 & 59.7 & 48.6 & 39.6 \\
\hline Males & $50(33$ & $39(60$. & 15 & $0(0 \%)$ \\
\hline Females & $98(66.2 \%)$ & $25(39.0 \%)$ & $21(58.3 \%)$ & $5(100 \%)$ \\
\hline
\end{tabular}




\section{Primary vs. Secondary CBD stones}

Twenty-six patients $(10.3 \%)$ had undergone cholecystectomy and all of them presented with cholecystectomy (mean interval - seven months from the date of cholecystectomy) within two years. Of the remaining 227 patients with an intact gallbladder, 173 patients had stones in the gallbladder $(68.4 \%)$. There was no association between age, gender or the clinical presentation and the presence of concomitant gallbladder stones.

\section{Anatomical associations}

Thirty-six (14.2\%) patients were found to have juxta-papillary diverticula. Patients with diverticula (mean age 54.7 years) were significantly older than patients without them (mean age 47.2 years, $p<0.001$ ) and were significantly more prone to present with jaundice than other complications of the disease considered in the study (Chi-square $p=0.013$ ). The patients with diverticula were more likely to have multiple stones (Fisher's exact test $p=0.030)$. Nine patients $(3.6 \%)$ were found to have CBD strictures, and brush cytology of all the strictures was benign and $21(8.3 \%)$ patients were diagnosed with choledochal cysts.

\section{Characteristics of the stones}

Table 2 illustrates the distribution of patients according to the stone burden i.e. the number of stones, size and location of them along the biliary tree.

Table 2. Distribution of patients according to the characteristics of the stones

\begin{tabular}{lrr}
\hline & Number of patients & Percentage \\
\hline Feature - Stone count & & \\
$\quad$ Single stone & 121 & $47.82 \%$ \\
2 stones & 27 & $10.67 \%$ \\
3 stones & 9 & $3.55 \%$ \\
Multiple stones & 96 & $37.94 \%$ \\
Feature - Position of the stone & 2 & \\
$\quad$ Intrahepatic & 17 & $0.79 \%$ \\
Proximal & 61 & $6.71 \%$ \\
Mid & 173 & $24.11 \%$ \\
Distal & & $68.37 \%$ \\
Feature - Size of the stone & 32 & $12.64 \%$ \\
$<0.5 \mathrm{~cm}$ & 85 & $33.59 \%$ \\
$0.5-1 \mathrm{~cm}$ & 124 & $49.01 \%$ \\
$1-1.5 \mathrm{~cm}$ & 12 & $4.74 \%$ \\
$>1.5 \mathrm{~cm}$ & & \\
\hline
\end{tabular}

\section{DISCUSSION}

A majority of the patients included in the study (85.8\%) presented with obstructive jaundice, cholangitis or acute biliary pancreatitis, all of which are considered as serious complications of the disease. The remaining study population had either distinct biliary colics or presented with non-specific upper abdominal pain. Consequently, inferences made from the results of this study are distinctive to the entity of symptomatic choledocholithiasis. There exist fewer studies on a similar sample of patients worldwide, although a number of studies have been published on the asymptomatic disease. Since patients included in the sample originated from various parts of the island, the findings can be generalized to the Sri Lankan population. Accordingly, this study describes the disease characteristics of a unique population.

Asian descent, increasing age and male gender are identified as risk factors for complicated choledocholithiasis. ${ }^{9,10}$ In this study, choledocholithiasis was found to affect middle-aged population with a female predominance. Females presented with this disease in an average 8.8 years earlier than males. Consequently, females were considered to be at increased risk for symptomatic choledocholithiasis in Sri Lanka. Older patients showed a tendency to present with cholangitis whereas younger patients showed a tendency to present with abdominal pain or biliary colic, thus confirming the fact that older patients had a more complicated disease. In a small prospective study carried out in Peru, the prevalence of cholangitis and biliary pancreatitis was found in $30.6 \%$ and $11.1 \%$ of patients with choledocholithiasis, ${ }^{11}$ both of which are higher than the findings of this study. Abdominal pain was reported in $94.4 \%$ of patients, and other complications of the disease were not investigated in the present study.

Juxta-papillary diverticula are well-known for their association with choledocholithiasis and for causing technical difficulty during biliary cannulation. ${ }^{12,13}$ The prevalence of juxta-papillary diverticula in our study population was lower (14.2\%) as compared to the reported studies demonstrating a prevalence of $26 \% .{ }^{14}$ Based on the current knowledge, higher prevalence of diverticula in older patients suggests an acquired etiology. ${ }^{15}$ Anatomical abnormalities in the biliary tree like choledochal cysts and 
CBD strictures facilitate stone formation. ${ }^{16,17}$ However, in the present study, only $8.3 \%$ and $3.6 \%$ of the patients had choledochal cysts and CBD stricture, respectively. Furthermore, the majority of stones were found in anatomically normal biliary systems.

The properties of stones are helpful in predicting the outcome of endoscopic clearance. Large, impacted, multiple or intrahepatic stones are considered difficult to extract and need more sophisticated methods like mechanical or laser lithotripsy. ${ }^{18,19}$ A majority of patients included in the study had single or distal CBD stones, the clearance of which is not a difficult task. Moreover, 95.24\% of patients had stones smaller than $1.5 \mathrm{~cm}$, which is also a favorable feature for successful endoscopic clearance. ${ }^{19}$ Therefore, the vast majority of the sample had a favorable stone profile despite the complicated nature of the clinical course.

The criteria to categorize CBD stones into primary or secondary stones were introduced by Madden ${ }^{6}$ in 1973 and amended later by Saharia in $1976 .^{7}$ Saharia et al. ${ }^{7}$ identified CBD stones as "the absence of a long cystic duct remnant or a biliary stricture from the previous cholecystectomy, at least a two-year symptom-free interval following cholecystectomy, and soft, light brown stones or sludge present in the common duct". All patients with intact gallbladder $(89.7 \%)$ were placed under secondary stone category based on the above-mentioned criteria. All the post cholecystectomy patients $(10.3 \%)$ were also placed under this category, as they presented with the symptoms within two years from the date of cholecystectomy. Therefore, the possibility of the presence of primary CBD stones in our patients was ruled out. Although the physical or chemical properties of the stones were not investigated in the present study, as they were beyond the objectives of the study, the presence of primary CBD STONE in the patients was ruled out because of the other two criteria. This highlights the need for a revision of the five-decade-old criteria.

CBD stones found in Sri Lankan patients are predominantly single, distal and small, which are the favorable features for successful endoscopic clearance. Elderly patients with CBD STONE should be given more attention because they tend to follow a more complicated disease course. None of the stones found in this study could be categorized into a primary CBD stone according to the available criteria, although most of the stones were found in an anatomically normal biliary tree. Consequently, a revision of the classification theory of CBD stones is necessary.

\section{ACKNOWLEDGEMENTS}

The authors wish to acknowledge the support extended by the staff of the endoscopy unit of the Colombo South Teaching Hospital, Kalubowila, Sri Lanka.

\section{REFERENCES}

1. Costi R, Gnocchi A, Di Mario F, Sarli L. Diagnosis and management of choledocholithiasis in the golden age of imaging, endoscopy and laparoscopy. World J Gastroenterol 2014;20:13382-13401.

2. Papalezova K, Clary B. Stones in the bile duct: clinical features and open surgical approaches and techniques. In: Jarnagin W, ed. Blumgart's surgery of the liver, biliary tract and pancreas. 5th ed. Philadelphia: Elsevier Saunders, 2013:532-540.

3. Tazuma S. Gallstone disease: epidemiology, pathogenesis, and classification of biliary stones (common bile duct and intrahepatic). Best Pract Res Clin Gastroenterol 2006;20:1075-1083.

4. Collins C, Maguire D, Ireland A, Fitzgerald E, O'Sullivan GC. A prospective study of common bile duct calculi in patients undergoing laparoscopic cholecystectomy: natural history of choledocholithiasis revisited. Ann Surg 2004;239:28-33.

5. Videhult P, Sandblom G, Rasmussen IC. How reliable is intraoperative cholangiography as a method for detecting common bile duct stones?: a prospective population-based study on 1171 patients. Surg Endosc 2009;23:304-312.

6. Madden JL. Common duct stones. Their origin and surgical management. Surg Clin North Am 1973;53:1095-1113.

7. Saharia PC, Zuidema GD, Cameron JL. Primary common duct stones. Ann Surg 1977;185:598-604.

8. ASGE Standards of Practice Committee, Maple JT, BenMenachem T, Anderson MA, Appalaneni V, Banerjee S, et al. The role of endoscopy in the evaluation of suspected choledocholithiasis. Gastrointest Endosc 2010;71:1-9.

9. Kummerow KL, Shelton J, Phillips S, Holzman MD, Nealon W, Beck W, et al. Predicting complicated choledocholithiasis. J Surg Res 2012;177:70-74.

10. Ko CW, Lee SP. Epidemiology and natural history of common bile duct stones and prediction of disease. Gastrointest Endosc 2002;56(6 Suppl):S165-S169.

11. Llatas Pérez J, Hurtado Roca Y, Frisancho Velarde O. [Choledocholithiasis in Edgardo Rebagliati Martins Hospital. Lima-Peru. 2010-2011. Incidence, risk factors, diagnostic and therapeutic aspects]. Rev Gastroenterol Peru 2011;31:324-329. Spanish.

12. Kennedy RH, Thompson MH. Are duodenal diverticula associated with choledocholithiasis? Gut 1988;29:1003-1006.

13. Kim MH, Myung SJ, Seo DW, Lee SK, Kim YS, Lee MH, et al. Association of periampullary diverticula with primary choledocholithiasis but not with secondary choledocholithiasis. Endoscopy 1998;30:601-604.

14. Hagège H, Berson A, Pelletier G, Fritsch J, Choury A, Liguory $\mathrm{C}$, et al. Association of juxtapapillary diverticula with choledocholithiasis but not with cholecystolithiasis. Endoscopy 1992; 
24:248-251.

15. Osnes M, Løotveit T, Larsen S, Aune S. Duodenal diverticula and their relationship to age, sex, and biliary calculi. Scand J Gastroenterol 1981;16:103-107.

16. Savader SJ, Benenati JF, Venbrux AC, Mitchell SE, Widlus DM, Cameron JL, et al. Choledochal cysts: classification and cholangiographic appearance. AJR Am J Roentgenol 1991;156:327-331.
17. Tan KC, Howard ER. Choledochal cyst: a 14-year surgical experience with 36 patients. Br J Surg 1988;75:892-895.

18. Stefanidis G, Christodoulou C, Manolakopoulos S, Chuttani R. Endoscopic extraction of large common bile duct stones: a review article. World J Gastrointest Endosc 2012;4:167-179.

19. McHenry L, Lehman G. Difficult bile duct stones. Curr Treat Options Gastroenterol 2006;9:123-132. 